\title{
Integrating GRACE products and land surface models to estimate changes in key components of terrestrial water storage in the Nile River Basin
}

\section{Zemede M. Nigatu}

Shanghai Jiao Tong University

Dongming Fan

Southwest Jiaotong University

Wei You ( $\square$ youwei@swjtu.edu.cn )

Southwest Jiaotong University https://orcid.org/0000-0003-0490-6996

Full paper

Keywords: GRACE Terrestrial Water Storage, groundwater storage change, soil moisture storage change, Nile River Basin, trend, uncertainty, SNR

Posted Date: June 16th, 2020

DOI: https://doi.org/10.21203/rs.3.rs-34754/v1

License: (c) (i) This work is licensed under a Creative Commons Attribution 4.0 International License. Read Full License 
Zemede M. Nigatu1,3, Dongming Fan1, 2, Wei You1, 2

1Faculty of Geosciences and Environmental Engineering, Southwest Jiaotong University, Chengdu 611756, China

2State-Province Joint Engineering Laboratory of Spatial Information Technology for High-Speed Railway Safety,

Chengdu 610031, China

${ }_{3}$ Geospatial Information Science (GIS) department, WGCFNR, Hawassa University, Hawassa, PO Box 5, Ethiopia Corresponding author: Wei You (youwei@swjtu.edu.cn)

Abstract

The Nile River Basin (NRB) is facing extreme pressure on its water resources due to an alarmingly increasing population that is extremely vulnerable in aspects of irrigation and hydropower. The NRB ascends itself to remotely sensed approaches with high resolution of spatial and temporal coverage as disparate to ground-based in-situ observations due to its size and limited access from basin countries. The Gravity Recovery and Climate Experiment (GRACE) allow a unique opportunity to investigate the changes in key components of Terrestrial Water Storage (TWS). Differences in tuning parameters and processing strategies result in GRACE TWS solutions with regionally specific variations and error patterns. We explored the spatiotemporal changes of the TWS time series, trend, uncertainties, and signal-to-noise ratio (SNR) among different GRACE TWS. We had also investigated the key terrestrial water storage components (surface water, soil moisture, and groundwater storage changes). The results show that the uncertainty of GRACE spherical harmonic (SH) solutions are higher than the mass concentration (mascon) over the NRB, and the Center for Space Research-mascons (CSR-M) noted the first best performance. Substantially, significant long-term (2003-2017) negative groundwater and soil moisture trend demonstrates a potential depletion over NRB. Despite an increase in precipitation and TWS time series, the rate of decline noted to increase rapidly from 2008, thus indicating the possibility of human-induced change ( e.g., for irrigation purposes). Thus, the result of this study provides a guiding principle for future studies in TWS change-related hydro-climatic change over NRB and similar basins.

Keywords: GRACE Terrestrial Water Storage; groundwater storage change; soil moisture storage change; Nile River Basin; trend; uncertainty; SNR

\section{Introduction}

The Nile is the world's longest river. It has a drainage area of about 3.2 million $\mathrm{km} 2$ that is nearly $10 \%$ of the landmass of the African continent. It flows across 11 countries from South to North with approximately 35 degrees of latitude, which crosses highly diverse landscapes and climatic zones. The two main tributaries of the Nile River basin (NRB) are the White Nile and the Blue Nile. NRB is facing extreme pressure on its water resources due to alarmingly increasing population (Siam et al., 2017) that is extremely vulnerable in aspects of irrigation, agriculture (Abtew et al., 2014; Multsch et al., 2017), water supplies, and hydropower (Ahmed et al., 2019; Hasan et al. ,2018). Owing to its size, the Nile inclines itself to remotely sensed approaches with the high spatial and temporal coverage as the NRB disparate to ground-based in-situ observations. Therefore, understanding its surface, soil moisture, and groundwater storage are crucial to 
providing useful information for proper water resource utilization and climate change impact studies.

The Gravity Recovery and Climate Experiment (GRACE) offer a unique opportunity to quantify and investigate the Terrestrial Water Storage (TWS) variations at regional and global scales. GRACE-derived TWS delivers vertically integrated water storage changes in all water-bearing layers. The integration, as indicated in Eq.1 (Ramillien et al., 2014), comprises four components. These are surface water storage in rivers, lakes, and wetlands $\left(\Delta S W S_{t}\right)$, soil moisture storage $\left(\Delta S M S_{t}\right)$, ice and snow water storage $\left(\Delta I S S_{t}\right)$, and groundwater storage $\left(\Delta G W S_{t}\right)$. Thus, GRACE measurements have become a crucial hydrological tool for quantifying basin-scale TWS (Hu \& Jiao, 2015). We used only three components (Castellazzi et al., 2016; Long et al., 2015) to assess spatiotemporal changes in TWS, assuming the contribution of ice/snow to be negligible over the NRB (Eq.1).

$$
\Delta T W S_{t}=\Delta S W S_{t}+\Delta S M S_{t}+\Delta G W S_{t}
$$

TWS represents the sum of all water stored above and below the Earth's surface. It is a significant component of the global hydrological cycle, counting water in lakes, rivers, wetlands, soil, humanmade, and groundwater reservoirs. TWS change controls the weather through a series of processes and feedback mechanisms that reflects the natural variability of climate (Yang et al., 2015). Thus, quantification and monitoring of TWS change are critical for characterizing changes in water resources and for improved prediction of regional-global water cycles and interactions with the Earth's climate system (Famiglietti, 2004).

GRACE's products are mainly in the form of traditional spherical harmonic (SH), and mass concentration (MASCONS) produced from different centers. These centers processed with different approaches, such as the variational equation integration approach, short-arc integral approach, energy conservation approach, celestial mechanics approach, and acceleration approach. The major drawback of the GRACE SH solutions is the coarse spatial resolution. In another way, spatial filtering required to suppress the spatial noise "over degree and order 30" for GRACE SH coefficients that are dominated by the longitudinal stripping noise (Swenson \& Wahr, 2006). These drawbacks further degrade the spatial resolution of GRACE's estimated mass changes (Chen et al., 2015).

Thus, GRACE mascon solutions had released to overcome the drawbacks of the SH. In GRACE mascon solutions, mass change products are not affected by the longitudinal stripes and do not 
require smoothing or filtering, and gives improved spatial resolution (Save et al., 2016; Wiese et al., 2016; Watkins et al., 2015). According to Wiese et al. (2016), the mascon solutions constrained by a priori information derived from near-global geophysical models to prevent striping and filtered by Coastline Resolution Improvement (CRI) to reduce spatial leakage from land to oceans. Furthermore, the Center for Space Research-mascons (CSR-M) the Glacial Isostatic Adjustment (GIA) corrected with ICE6G-D model (Peltier et al., 2018), C20 (degree 2 order 0) coefficients replaced with solutions from Satellite Laser Ranging (Cheng et al., 2013) in Release-06 (RL-06) version. The three mascons (i.e., Center for Space Research mascon (CSR-M), Goddard Space Flight Center mascon (GSFC-M), and Jet Propulsion Laboratory-mascon (JPL-M) differ in terms of grid cell scale and observation equations (Loomis et al., 2019; Wiese et al., 2018; Save et al., 2019). Details of these data presented in Table 1.

Additionally, TWS of different GRACE solutions has studied at the global and basin level. Ensemble prediction and inter-comparisons of the SH solutions were recommended by (Sakumura et al ., 2014) due to reduced noise in the gravity field solutions within the available models. At the global level (Scanlon et al., 2016);(Save et al., 2016) studied the global trends and annual amplitudes by comparing the mascon with $\mathrm{SH}$ solutions and recommended mascon solutions for accurate surface-based gridded information used without further postprocessing. At basin level, (Shamsudduha et al., 2017) used JPL-M and GRACE Tellus products that highlighted the substantial uncertainty in the amplitude of Terrestrial Water Storage Anomaly (TWSA). None of those mentioned above studies considered a recently released GSFC mascon solution. Some river basins experienced discrepancies between GRACE solutions (Scanlon et al., 2018) that leads to significant inconsistencies in TWSA trend estimations. Hence, evaluating those discrepancies is urgent for understanding uncertainties in monitoring water resources variations based on basin scales.

GRACE and GLDAS (Global Land Data Assimilation System) have provided useful observations for studying water resources around the world, particularly over regions with insufficient in-situ measurements (e.g., Bonsor et al., 2018; Chen et al., 2019; Scanlon et al., 2018). Recently several studies (e.g., Hasan et al., 2018; Mehrnegar et al., 2020; Seyoum, 2018; Shamsudduha et al., 2017) have used GRACE observations to explore changes in TWS in the Nile River Basin (NRB). Though, their conclusions are inconsistent because of different solutions for the GRACE observations used for investigative changes of TWS. Thus, it highlights the demand for evaluating the performance of each GRACE product in the NRB region. 
Despite the efforts above, a comprehensive long-term study of critical water storages (terrestrial water, surface water, soil moisture, and groundwater storage) distinctly, as well as their fluctuations over the whole NRB, is missing. The current study addresses these missing gaps by manipulating GRACE, other multi-satellite, and surface models' outputs. Thus, the nobility or scientific contribution in this study is to use temporal (January 2003 to June 2017) TWS GRACE data in line with the land surface models (LSMs) outputs to produce enhanced estimates of groundwater in the NRB. This study extends the prior research findings by (i) utilizing enhanced state-of-the-art GRACE solutions, the global mass concentration (mascons) solutions; (ii) employing outputs from numerous LSMs to isolate the GRACE-derived groundwater storage (GWS) from the GLDAS; and (iii) evaluating the performance of three $\mathrm{SH}$ and three Mascon solutions against in situ observations of rainfall and satellite altimetry over NRB.

The main objective of this study is to explore differences between different GRACE solutions over NRB and evaluate the uncertainty arises from the selection of GRACE solutions that causes discrepancies on key components of TWS (soil moisture storage (SMS), surface water storage (SWS), and GWS). Furthermore, this study had explored the spatiotemporal pattern of GRACE TWSA, SMS, SWS, and GWS time series, trends, and uncertainties among different GRACE solutions. This paper is structured as follows: A brief description of each GRACE TWSA solution, datasets used in this study, and detailed methodology presented in section two. The times series analysis, signal-to-noise ratio (SNR), uncertainty, the trend of GRACE solutions, and their multisolutions ensemble mean (Ens-SH) are evaluated in the research versions in section three. Lastly, the results of the study and the conclusions presented in section four.

\section{Materials and Methods}

\subsection{Study area description}

The Nile River Basin (NRB) is the world's longest river basin with a total flow length of over $6,700 \mathrm{~km}$. Its drainage basin covers approximately $3,046,334 \mathrm{~km} 2$ that accounts for an equivalent to $10 \%$ of Africa's landmass (see Figure1). The NRB comprises 11 countries (Burundi, Democratic Republic of Congo, Egypt, Eritrea, Ethiopia, Kenya, Rwanda, South Sudan, Sudan, Tanzania, and Uganda). More than 400 million people inhabit the basin (2012 estimate), and by the year 2030, the population projected to rise to 700 million. According to (Abtew \& Melesse, 2014), it raises concerns about sustainable and equitable management of the basin's resources. 
Based on the hydro-climatic condition and recommendation of (Awange et al., 2014), we divided the NRB into four key areas of interest: (1) The Blue Nile Region (BNR) comprises a total area of $300,000 \mathrm{~km} 2$. It mostly belongs to Ethiopian Highlands, including both the Upper and Lower Blue Nile region with Binda Rahad Region. (2) Lake Victoria Region (LVR) has a total area of 258,000km2 representing Lake Kyoga, Albert, George, and Semilik basin. It is the headwaters of the White Nile. (3) The Bahr-el-Ghazal Region (BER) that has a total area of 526,000km2. It represents the Congo-Nile River divide tributaries and the vast area of Sudanese plain with a low slope, which is the leading western tributary of the Nile. (4) Main Nile Region (MNR) has a total area of $258,000 \mathrm{~km} 2$. Therefore, all NRB sub-basins (regions) exhibit more considerable spatial coverage that enables us to detect changes in TWS GRACE Satellite data. In this paper, the term region used to represents sub-basins of NRB interchangeably.

\subsection{GRACE data}

The GRACE data accessed from four official processing institutions. These are NASA Goddard Space Flight Center (GSFC), Center for Space Research at Texas State University (CSR), Geoforschungs Zentrum Potsdam (GFZ), and Jet Propulsion Laboratory (JPL). The processing institutions used different parameters and strategies, such as different background force models, data pre-processing approaches, local parameters, arc length, etc.

The TWS RL06 data of three SH solutions (CSR-SH, GFZ-SH, and JPL-SH) acquired from https://grace.jpl.nasa.Gov and http://geoid.colorado.edu/gracel. Numerous filtering methods used to remove north-south striping errors and correlated errors (Duan et al.,2009; Chambers \& Bonin, 2012), most of which are empirical. In this study, we used the Level-3 GRACE data filtered by a de-striping technique to remove the correlated error (Swenson \& Wahr, 2006). The SNR is already significantly improved (Göttl et al., 2018) in RL06 and posterior correction models (Fagiolini et al., 2015). The mass concentration (mascon) product is a recent advanced form of gravity field basis function. It is a much more rigorous approach comparing with the SH approach due to easy use for both geodesists and non-geodesists to implement the geophysical constraints without any postprocessing. In this study, we used three SH (CSR-SH, GFZ-SH, and JPL-SH) with their ensemble mean (Ens-SH) and three mascons (CSR-M, JPL-M, and GSFC-M) solutions (see Table 1) in a total of 7 solutions. 


\subsection{Ensemble modeling}

The ensemble model could reduce the noise seen in the scattering of individual solutions. According to (Sakumura et al., 2014), a weighted mean of the ensemble components will result in an over-all solution with a much higher level of reliability than a stand-alone model. Each GRACE solution is assumed to represent the truth plus a certain amount of error representing a relatively uniform scatter about this mean value. In this study, the ensemble model produced by composing the weighted mean of three SH GRACE solutions.

\subsection{The amplitude of the GRACE TWS}

The amplitude of the GRACE TWS signal was affected by different processing techniques. The smoothing filters and "de-striping" were applied to SH solutions by GRACE processing centers to reduce the noise level, which could reduce and smooth the amplitude of the water mass variations (Wouters et al., 2014). They also noted that the processing treatments and the truncation of the spherical harmonic degree suffer from leakage error. The leakage error impacts water mass that tends to be spatially spread and can "leak" toward nearby water mass. The global grid of timeinvariant scaling factors computed by (Landerer \& Swenson, 2012) using the CLM4 global hydrological model could overcome such leakage to some extent. Details of these data (three SH and mascon solutions) used in this study are given in Table 1.

\subsection{Rainfall data}

Rainfall in the Nile River basin has been recorded since the beginning of the 20 th century using the manual as well as automatic recording rain gauges. In this study, we used the rain gauge data collected from various sources. It includes respective countries' hydro-meteorological departments in the basin as well as from researchers in the region. Furthermore, to fill the missing gap and basin-wide representation, we had used Tropical Rainfall Measuring Mission (TRMM) 3B43 precipitation V7 data (1998 to 2016). TRMM satellite precipitation data is available and downloaded from the NASA website (https://trmm.gsfc.nasa.gov/). We used the TRMM-3B43 ( (see Table 1) Level 3 satellite-gauge (SG) combination data set to estimate the precipitation over NRB. The weighted areal mean technique is applied to determine the rainfall magnitude at the subbasin (regions) and basin level.

\subsection{Groundwater storage}

Groundwater storage $\left(\Delta G W S_{t}\right)$ changes are estimated in regional-scale (Richey et al., 2015; Ramillien et al., 2014) by computing total terrestrial water storage anomalies $\left(\Delta T W S_{t}\right)$ from one or more GRACE products and deducting changes in other terrestrial stores simulated by LSMs. In 
the $\mathrm{NRB}$, it comprises changes in soil moisture $\left(\Delta S M S_{t}\right)$ and surface water $\left(\Delta S W S_{t}\right)$ storage change (Eq. (2)).

$$
\Delta G W S_{t}=\Delta T W S_{t}-\left(\Delta S M S_{t}+\Delta S W S_{t}\right)
$$

To derive $\Delta G W S_{t}$ from GRACE $\Delta T W S_{t}$ (Eq. (2)), we used simulated soil moisture to represent $\Delta S M S_{t}$ and surface runoff, as a proxy for $\Delta S W S_{t}$ as presented in (Bonsor et al., 2018) after (Thomas et al.,2017); Mishra et al., 2016) that applied to derive from LSMs of NASA's Global Land Data Assimilation System (GLDAS). GLDAS is an uncoupled land surface modeling system that includes multiple global LSMs (Rodell et al., 2004), driven by the observed surface atmospheric fields (Sheffield et al., 2006). We apply monthly $\Delta S M S_{t}$ and surface runoff data at a spatial resolution of $1^{\circ} \times 1^{\circ}$ from 4 GLDAS LSMs: the Community Land Model CLM-version 2 (Dai et al., 2003), the Noah model NOAH-version 2.7.1 (Ek et al., 2003), the Variable Infiltration Capacity VIC-model-version 1.0 (Liang et al., 2003), and the Mosaic model MOSAIC-version-1.0 (Koster et al., 1992).

\subsection{Satellite Altimetry of Major Lakes}

The Water level estimation by satellite altimetry developed and optimized for open water bodies (Moore \& Williams, 2014; Uebbing et al., 2015). In this study, NRB major lakes satellite altimetry-derived surface water observations used to validate GRACE products TWSA. The Satellite altimetry time series (1992 to the present-day) of major global lakes are available at (https://ipad.fas.usda.gov/), the U.S. Department of Agriculture (USDA). This database includes repeated observations of the TOPEX/Poseidon (T/P), Jason-1, and Jason2/OSTM altimetry missions. In this study, we used satellite altimetry-derived surface water observations to evaluate the performance of GRACE TWS (Table 2). Details of these data are given in Table 1.

\subsection{Soil moisture changes}

Data from three different sources (GLDAS, WGHM, and ERA-Interim) merged using the Triple Collocation Analysis (TCA) (Gruber et al., 2017) after (Stoffelen, 1998) for reliable estimates of soil moisture changes over the NRB (see Figure 2). TCA offers an alternative method for estimating random error variances (Gruber et al., 2017) in the absence of ground reference data. TCA is applied here to merge soil moisture outputs;

$$
\begin{gathered}
S_{1}=\alpha_{1} S_{t}+e_{1} \\
S_{2}=\alpha_{2} S_{t}+e_{2} \\
S_{3}=\alpha_{3} S_{t}+e_{3}
\end{gathered}
$$


with $S_{t}$ being the actual soil moisture variation, $S_{1}, S_{2}$, and $S_{3}$ represents three soil moisture anomalies related to $S_{t}$ with $\alpha_{1}, \alpha_{2}$ and $\alpha_{3}$ being the coefficients that correspond to the errors of $e_{1}$, $e_{2}$, and $e_{3}$, respectively. The objective is to estimate error variances associated with $e_{1}, e_{2}$, and $e_{3}$ to be used in the weighting process. On the one hand, TCA solves this by considering the errors of the products to be independent of each other. On the other hand, it arbitrarily assumes any of the products as a reference ( see Yilmaz et al., 2012) for more details regarding TCA' implementation.

Supposing the errors of the products are independent of each other and from the truth, and assuming a mutual linear relationship between the actual soil moisture and these estimates, the error variances $\left(\sigma^{2}\right)$ are calculated based on Eqs. 6-8:

$$
\begin{aligned}
\sigma^{2}{ }_{1} & \left.=\overline{\left(S_{1}-S_{2}\right)\left(S_{1}-S_{3}\right.}\right) \\
\sigma_{2}^{2} & \left.=\overline{\left(S_{2}-S_{1}\right)\left(S_{2}-S_{3}\right.}\right) \\
\sigma_{3}^{2} & \left.=\overline{\left(S_{3}-S_{2}\right)\left(S_{3}-S_{2}\right.}\right)
\end{aligned}
$$

Selecting any of the products as the reference will not no impact the merged time series (Gruber et al., 2017). The error variances calculated from Eqs. (6) - (9) used in Eqs. (9) - (11) to estimate weights of each merged product where $\sigma_{1}^{2}, \sigma_{2}{ }^{2}$, and $\sigma_{3}{ }^{2}$ are error variances of $S_{1}, S_{2}$, and $S_{3}$, respectively, with the corresponding weights of $w 1, w 2$, and $w 3$.

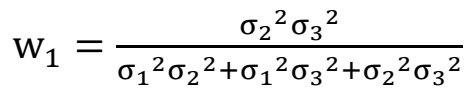

$$
\begin{aligned}
& \mathrm{w}_{2}=\frac{\sigma_{1}{ }^{2}{\sigma_{3}}^{2}}{\sigma_{1}{ }^{2} \sigma_{2}{ }^{2}+{\sigma_{1}}^{2}{\sigma_{3}}^{2}+\sigma_{2}{ }^{2}{\sigma_{3}}^{2}}
\end{aligned}
$$

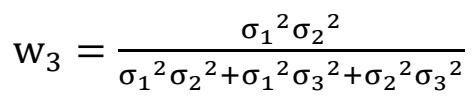

The final merged soil moisture estimate $\left(S M_{T C A}\right)$ estimated as presented in (Eq.12), where $\mathrm{w}_{1}, \mathrm{w}_{2}$, and $\mathrm{w}_{3}$ are the relative weights of soil moisture $S_{1}, S_{2}$, and $S_{3}$, respectively.

$$
S M_{T C A}=w_{1} S_{1}+w_{2} S_{2}+w_{3} S_{3}
$$

\subsection{Time series decomposition and trend analysis}

The GRACE TWSA monthly time series (TS) data needs seasonal trend decomposition to remove seasonality from the original TWSA series (Andrew et al.,2017a) after filling missing data. The missing data can be filled by a simple temporal interpolation method (Andrew et al., 2017b) or by averaging the values of the two or more months either side. The harmonic analysis is a commonly 
implemented approach (Scanlon et al., 2016) and the seasonal trend decomposition using Loess (STL) exhibited similar decomposed results with harmonic analysis(Scanlon et al., 2018). In this study, the STLplus approach of LOESS (LOcal regrESSion) smoothing that is modified by (Ryan Hafen, 2016), which was initially introduced by (Cleveland et al., 1990), is used due to adaptability and robustness to decompose time series (see Eq. (13)).

$$
S_{\text {total }}=S_{\text {long term }}+S_{\text {seasonal }}+S_{\text {residual }}
$$

Where it consists of inner and outer loops with a sequence of smoothing operator LOESS and generates three components from a time series; the original signal $\left(S_{\text {total }}\right)$ represented as the sum of a long-term part $\left(S_{\text {long term }}\right)$, a seasonal cycle $\left(S_{\text {seasonal }}\right)$, and the remaining sub-seasonal

residuals $\left(S_{\text {residual }}\right)$. The long-term component $\left(S_{\text {long term }}\right)$ further divided into long-term linear trends and long-term nonlinear (inter-annual variability). The residuals reflect both sub-seasonal signal and noise (Humphrey et al., 2016); these high-frequency residuals anticipated being a combination of both the noise and a real signal that represents sub-seasonal water storage variability that is present in the GRACE data. Details of the STL decomposition approach presented in (Lu et al., 2003).

Thus, the TWS trends refer to the linear trends estimated from the long-term deseasonalized) after STL analysis. Moreover, the modified Mann Kendall Trend Test (M-K test) is used to identify patterns from the deseasonalized TWSA series. Yue et al. (2002) recommend the modified M-K test for a nonparametric and vigorous test for determining a trend in a time series. Detailed procedures presented on the respective reference given in appendix 2.

\subsection{Uncertainty Estimates of GRACE solutions TWS}

Uncertainties of all solutions estimated in this study are the Root mean square (RMS) of residuals of TWSA. The residuals are reminders after removing long-term trends, interannual, and seasonal signals ( i.e., $\geq 13$ months) per the recommendation of (Scanlon et al., 2016). It may overestimate actual uncertainties since the residuals may contain sub-seasonal signals in accumulation to noise. Leakage errors calculated using synthetic simulations as described in (Wiese et al., 2016) and the shape of the river basin imitates to the placement of the mascons, associated with the spatial distribution of mass at sub-mascon spatial scales according to geophysical models, which were considered by leakage errors. These errors from the differences between original TWSA from the CLM4 LSM and the filtered TWSA applied with the scaling factors (Landerer \& Swenson, 2012). 


\section{Results and Discussion}

This section presents the data analysis results and provides a brief discussion about TWSA time series, trend (GWS, SWS, SMS), and uncertainty over NRB and sub-basin. In sequential order time series over NRB, GRACE TWSA trends and uncertainties over NRB discussed below. Finally, the results of the spatiotemporal analysis of trends and uncertainty in the sub-catchments of NRB presented.

The performance of the seven GRACE products such as mascons CS-M, GSCFC-M, and JPL-M and spherical harmonics solutions CSR-SH, GFZ-SH, JPL-SH, and Ens-SH evaluated in relation with the equivalent water height of satellite altimeter and GRACE TWS. From the view of correlation coefficients and RMSE, the CSR-M product performed the best. Over 60 basins around the world evaluated by(Long et al., 2015; Scanlon et al., 2018), the mascon solution performed better than other GRACE products (see details in Table 2), and thus it shows consistent with our study.

\subsection{Time series over NRB}

The overall seasonal cycle is captured very accurately and similarly for all GRACE TWSA except magnitude variations among the solutions (Figure 3a) over the NRB. It is most likely that the changing reservoir storage information is overestimated or underestimated in the GRACE basin average. In general, the time series of TWSA derived from six solutions and Ens-SH show a similar pattern of interannual fluctuations between 2004 and 2011. Contrarily the variation increases after 2013. The CSR-SH TWSA overestimation compared with the rainfall data is higher during 2003, 2008, and 2017. Similarly, GFZ-SH and JPL-SH also show overestimation. This overestimation likely misrepresents hydro-climatic extreme events such as drought and flood events. As shown in Figure 3b, the TWSA time series showed negative storage between 20032006 and 2008-2010, revealing NRB basin-wide water storage deficit. Thus, TWSA over the NRB experienced two decreasing periods (2003-2006, 2008-2010) and one strictly increasing period (2010 to 2017). The water storage across the basin is lost a rate of $-1.56 \mathrm{~cm} / \mathrm{yr},-1.32 \mathrm{~cm} / \mathrm{yr}$ from 2003 to 2006 and 2008 to 2010, respectively. Since 2010, the NRB water storage rises at a rate of $0.84 \mathrm{~cm} / \mathrm{yr}$ (2010 to 2017) and recovered of the water lost during the previous declining period. Different GRACE solutions compared over global river basins (Haddeland et al., 2011) that show variations between the available solutions that strongly impact the hydrological information within the data. Sakumura et al. (2014) noted the solutions all varied from the mean $1-1.5 \mathrm{~cm}$ level regardless of basin size over 156 global river basins. Thus, these differences among the solutions 
arise signal or extent of the regional signal and support the hypothesis that inconsistence among the solutions is due to random error rather than signal differences.

\subsection{GRACE TWSA trends and uncertainties over Nile River Basin}

GRACE TWSA time series data decomposed by using the STLplus techniques in terms of the long-term trend and seasonal TWSA signals (Figure A1), and the residual presented in (Figure A1 (a-d)). The seasonal signals removed by STLplus deseasonalization performed in (Appendix 1 Figure A1d shows the capacity of STLplus to remove the seasonal variations from the original GRACE TWSA time series. According to the derived signals, the seasonal pattern of TWSA is similar to that of precipitation in NRB. It is lower in winter (dry season) and higher in summer (primary rainy season). Therefore, summer precipitation dominates the annual Rainfall in NRB (Onyutha \& Willems, 2015), and abundant rainfall brings an increase in TWSA and water reserves in summer.

The trends of the three SH, their ensemble model, and three mascons TWSA derived from the long-term time series summarized in Figure 4. TWSA trends estimated from the solutions of the SH (JPL-SH, CSR-SH, and GFZ-SH) and mascon (CSR-M, JPL-M, and GSFC-M) shows the agreement of an increasing pattern but the different rate of the trend Figure 4a. The TWSA increasing trend rate of GFZ is the highest $(+0.57 \mathrm{~cm} / \mathrm{yr})$, and JPL-SH is lowest $(+0.37 \mathrm{~cm} / \mathrm{yr})$ while the ensemble model noted $(+0.51 \mathrm{~cm} / \mathrm{yr})$. The nonlinear trend (inter-annual variability) of all solutions revealed a similar pattern except magnitude differences. AS shown in Figure 4b, the magnitude variation is higher during (2006, 2008, and 2015) and very higher after the 2011 period showing the highest for GFZ-SH and JPL-SH. These periods are drought periods over NRB, and the interpretation of GRACE TWS magnitude is critical in terms of such hydro-climatic extreme events.

GRACE solutions mean annual cycles TWS have similar amplitude and phase over the Nile River basin and its sub-basins BNR and LVR (see Figure 5 (a-c)). Over NRB, some of the GRACE TWS have their maximum values in August while most of them 1-month lag for which is in September. Thus, the mean annual cycles are very close, with similar amplitudes, but with the 1month delay between GRACE and Rainfall. Similarly, a recent study (Zhang et al., 2019) shows a 1-month lag between GRACE TWSA and Rainfall for most of the global basins areas, which are mainly in Africa. Generally, it looks that some GRACE solutions provide meaningful observation for the NRB and its sub-basin hydrological studies. 
The LVR has two main rainy seasons, while the BNR has only one rainy season. On both subbasins, the main rainy season rainfall and GRACE TWS amplitude show higher agreement while less-rainy season the pattern shows less agreement. Similarly, the arid area of the NRB (BER and MNR) region has an erratic type of rainfall and a smaller amplitude of their seasonal cycle. In these sub-basins, the GRACE TWS and rainfall amplitude show less agreement. Over MNR, Rainfall has no cyclic/ seasonal pattern with an average of $2.83 \mathrm{~mm}$ from 1901 until 2015 and a record low of $0.21 \mathrm{~mm}$ in November of 2010. Thus, in this study, MNR sub-basin rainfall was not used to compare with the GRACE TWS seasonal amplitude.

In general, CSR-M shows the highest (78-90\%) agreement over NRB and GSFC-M show lower (77-85\%). In contrast, SH shows the lowest (25-74\%) agreement with Rainfall over NRB and its sub-basin Figure 5a. Overall comparison of the similarities and differences among GRACE solutions over NRB performed in the above section, before undertaking a detailed analysis of the terrestrial water storage anomaly within each sub-basin. Spatio-temporal variation and difference among the GRACE solutions TWSA presented in (Figure 5 (a-d)) for the whole NRB, Bahr-elGhazal Region (BER), and Blue Nile region (BNR) mostly parts of Ethiopian Highlands, and Lake Victoria Region (LVR).

\subsection{Groundwater result}

The result of TCA shows the average estimated soil moisture variation from GLDAS, WGHM, and ERA-Interim over the Nile regions Figure 7. Moreover, using the soil moisture and TWS changes, groundwater changes calculated based on (Eq. 1 \& 2) are also presented in Figure 6 - 7. Following the patterns of TWS and precipitation time series in (Figure 7), smaller soil moisture and groundwater variations exist over the Main Nile River Region and to a lesser degree over the Blue Nile Basin Region compared to the Lake Victoria Region. At the same time, no significant trend observed in soil moisture variations. The seasonal variabilities for Main Nile River Region time series have considerably lower magnitudes in comparison to other regions. Individual small variability has recently been shown by (Ahmed \& Abdelmohsen, 2018) over the Main Nile River Region can generally be explained by a lower precipitation rate Figure 7.

Over different regions on NRB groundwater changes exhibit short-term and long-term trends. Predominantly, over the Lake Victoria and Blue Nile Region, the negative trends can be seen between (2003-2006 and 2007-2009), followed by notable increases, probably due to the similar reasons clarified earlier studies (Awange et al., 2008; Seyoum, 2018). Pre-eminently, a negative groundwater trend is prevailing over the Main Nile River Region during the entire study period 
regardless of precipitation trends. After 2008 the rate of this decline is found to be larger, which shows substantial groundwater depletion over the region. The impact of the 2007 ENSO and reducing water controls in the Lake Victoria Region after 2006 likely caused groundwater increase over the Blue Nile Basin and Lake Victoria Region.

Though, this effect found to be tumbledown by 2008 follow-on in negative trends (with a higher rate for the Main Nile River Region) between 2008 and 2012. The groundwater to rise in both Lake Victoria and Blue Nile Region due to the increasing amount of precipitation after 2012. Similarly, the high rainfall has the same impact on soil moisture variation between 2012 and 2019. The spatial pattern maps generated (Figure 7) for three water storage compartments such as surface water storage, groundwater, and soil moisture variations that are time series averaged over each grid point for the period of 2003 to 2019. The Blue Nile Basin Region does not show a substantial change in most of the cases. Significant variations in terms of amplitude are found in the Lake Victoria region, thus confirming the previous findings. The Main Nile River Region depicts a negative trend in the groundwater, indicating extensive usage for irrigation (Abtew \& Melesse, 2014; Sultan et al., 2013). The Bahr El Ghazal (BER) region also shows a considerable decline in groundwater and soil moisture.

The critical water storage components retained different trends (Figure 8 \& 9) at various locations in the basin to enlighten the TWS change and its spatial variability across the NRB. SWS trend is an essential contributor to TWS show increasing trend (+0.1 to $0.6 \mathrm{~cm} / \mathrm{year})$ across the Congo River basin dived, BNR, and LVR portion of the NRB region while showing a decreasing trend across MNR. This increase is due to the presence of significant surface Lakes such as Lake Tana, Lake Victoria, Lake Albert, and Lake Koga.

Similarly, a more significant share of LVR and BNR experienced increasing trend due to the presence of major natural lakes and reservoirs in the equatorial Lake Region and Lake Tana while in MNR region the decreasing trend (0.1 to $0.6 \mathrm{~cm} / \mathrm{year})$ of SMS, SWS, and GWS due to intensive irrigation.

\subsubsection{Main Nile Region (MNR)}

The main Nile River (MNR) region is located in the northern part of NRB. It covers significant water resources such as Lake Nasser, Aswan high dam, and Nile delta in the Western Plateau within the Nubian Aquifer. The GRACE's TWS (Figure $8 \&$ 9d) indicates a declining trend of stored water, while discrepancy among the GRACE solutions in terms of magnitude and pattern of the trend is very high. In the MNR region, the water lost consistently (Figure A3d ) that may be 
due to two factors (Sultan et al., 2013). The first factor is that most of the water extracted from the Nubian Aquifer used for agricultural purposes such as the East Uweinat project that has seen heavy utilization of groundwater. In the East Uweinat project, the lands reclaimed amounted 1200 ha(1992), 4200 ha (2003), 75,000 ha by 2022, all of which will irrigate using groundwater as depicted by (Sultan et al., 2013). The second factor is the fact that the Uweinat-Aswan uplift prevents recharge of groundwater flowing from the South to the North.

\subsubsection{Blue Nile Region (BNR)}

The eastern part of NRB known as the Blue Nile River Region (BNR) that contributes over $80 \%$ (Berhanu et al., 2016) of the NRB flows and comprises Lake Tana and Grand Renaissance Dam (under construction). The BNR water storage (see on appendix Figure A3a) deficit observed from 2003 to 2006 and 2007 to 2010, while excess water storage found from 2011 to 2017. Thus, the equivalent water height loss of $1.6 \mathrm{~cm}$ in (2003-2006), 1.29cm in (2007 -2010), and gain of $3.6 \mathrm{~cm}$ in (2011 to 2017) noted. During the whole study period, 2003-2017, water storage show an increase of TWSA, and water storage increase approximately $1.56 \mathrm{~cm}$ equivalent water height. All GRACE's TWS solutions revealed an increasing trend for the whole period (see Figure 9a). During those above two decreasing periods, trend analysis indicates TWSA decease at the rate of $0.38 \mathrm{~cm} / \mathrm{yr}$ and $0.69 \mathrm{~cm} / \mathrm{yr}$, respectively. While from 2011 to 2017 , it shows increasing trend at a rate of $0.55 \mathrm{~cm} / \mathrm{yr}$ and from 2003 to 2017 at the rate of $0.42 \mathrm{~cm} / \mathrm{yr}$ that reasonably agree with previous studies (Seyoum, 2018; Baldassarre et al., 2011).

\subsubsection{Lake Victoria Region (LVR)}

Lake Victoria Region (LVR) located in the southern part of NRB, and it is a source of the White Nile comprising Lake Victoria, Lake Albert, and Lake Tanganyika. In LVR (see on Figure A3b) significant drop in the most water storage occurred from 2003-2006 (-0.36cm/yr) while 2006 onward, it increases with a rate of $0.14 \mathrm{~cm} / \mathrm{yr}$, and the water storage gain is $9.2 \mathrm{~cm}$ in equivalent water height. The rising and declining trend show reasonable agreement with (Swenson \& Wahr, 2009; Awange et al., 2008). The GRACE TWSA decrease between 2003-2006 is highly associated with the expansion of the Owen Falls dam/ Nalubale dam (Swenson \& Wahr, 2009). On the contrary (Becker et al., 2010) reported an increase in precipitation from the end of 2005 due to the El Niño-Southern Oscillation (ENSO) effect explained as anthropogenic and climate variability contributions. The individual water balance terms retrieved from satellite altimetry by (Vanderkelen et al., 2018) indicate the increase of water level in the LVR from 2011 onwards. 


\subsubsection{Bahr-El-Ghazal Region (BER)}

The Bahr El Ghazal Region (BER) represents rivers that originate from the Congo-Nile River divide in the Eastern part of NRB. Nearly all (i.e., about 96\%) the BER runoff and precipitation is evaporated or leaked into swamps (Conway \& Hulme, 1993). The GRACE TWS (Figure 3c) estimation indicates high interannual variability among the GRACE's solutions. The BER water storage (see on appendix Figure A3c) declined at a rate of $0.21 \mathrm{~cm} / \mathrm{yr}$ during 2008-2011.

Meanwhile, it increased at the rate of $(0.05,0.12$ and 0.02$) \mathrm{cm} / \mathrm{yr}$ between $2002 \& 2007$, 2012\&2017, and during the whole study period (2002-2017), respectively. The region also lost $0.39 \mathrm{~cm}$ in (2008-2011) and gained back $1.29 \mathrm{~cm}$ during 2012-2017. In general, it increased by approximately $0.52 \mathrm{~cm}$ equivalent water height from 2002 to 2017.

Over NRB sub-basins BNR and LVR (Figure 9 a-b), all solutions indicate an increasing trend with a slight variation of the rate of the pattern. Far from it, in the BER and MNR (Figure c-d) rising and declining trend, discrepancy noted among GRACE solutions TWSA trend (FigureB1). Over the BER region (Figure 9c), the overall trends statistically significant (p-value <0.05) and are slightly rising $(+0.24$ to $+0.13 \mathrm{~cm} / \mathrm{yr})$ except for the decline of JPL-SH. These discrepancies among the solutions exhibited higher over MNR (Figure 9d), which shows a slightly increasing for JPL-SH and the CSR-SH. On the contrary, for the rest of SH and mascon solutions, the decreasing trend noted. Similar trends are reported by (Shamsudduha et al., 2017) that agree with our study that shows a slightly rising trend $(0.04-1.0 \mathrm{~cm} / \mathrm{yr})$ except declining trends observed from the period of 2003 through 2006. Similar to the LVR region, the BNR regions all GRACE TWSA trend also exhibited a slightly increasing trend ranging from highest (JPL-M) to lowest (CSR-M).

Since the ensemble model may contain all the information from all the models, if some individual models have low accuracy, they will do affect the ensemble model. So, the ensemble model ignored, and the SNR index used to evaluate the quality of the different models. The SNR equals trend divided by uncertainty.

The uncertainty of GRAC solutions (in $\mathrm{cm}$ ) is higher for $\mathrm{SH}$ solutions ranging from \pm 0.85 (GFZ$\mathrm{SH})$ to \pm 0.34 (JPL-SH) than mascon solutions that are \pm 0.21 ( CSR-M), \pm 0.23 (GSFC-M), and \pm 0.32 (JPL-M) over NRB as summarized in Table 2. Similarly, over sub-basins also SH solutions exhibited higher uncertainty than the mascon solution, while the ensemble model shows moderate inconsistency. Correspondingly, recent studies (Save et al., 2016; Wiese et al., 2016; Watkins et al., 2015) agree with our study results showing the improvements of GRACE processing from traditional SH to mascon solutions have increased the signal-to-noise ratio and minimized 
uncertainties. Discrepancies in TWSA trends over MNR and BER regions likely related to the disparity in GRACE solutions. It is recommended to use GSFC-M TWS to reduce these discrepancies.

The deviation from the ensemble model and variation of the trend among solutions are unsatisfactory to describe the relative quality of TWSA solutions of each processing center. Henceforward, the signal-to-noise ratio (SNR) for each GRACE solution estimated as the ratio between the uncertainties and trend of the time series of TWSA.

Over the NRB, CSR-M performed best with the highest SNR and lowest uncertainty (see Table 2) that is followed by GSFC-M, while GFZ-SH showed the most inferior performance. Based on correlation and their Root mean square error (RMSE) with satellite Altimetry also CSR-M show the highest correlation $\left(\mathrm{R}_{2}=0.87\right)$ and lowest $(\mathrm{RMSE}=0.52)$ followed by GSFC-M and JPL-M, respectively. In the NRB sub-basins (MNR, LVR, and BER) also mascon solutions performed very well while all SH performs the poorest.

\section{Conclusion and Recommendation}

This study compared and discussed different GRACE TWS solutions and their effects on the spatial-temporal variations of GWS, SMS, and SWS estimated in the NRB, which implicit that one should cautiously select suitable TWS solutions for future studies. The long-term TWS compartments (groundwater, soil moisture, and surface water storage) simulated using land surface models as well as multi-mission satellite products. Complimentary consistency between the CSRM TWS and the satellite altimetry over the NRB that fully demonstrated the potential of GRACE data in monitoring changes in water (GWS, SWS, and SMS) dynamics over the NRB. Nevertheless, the extended groundwater level monitoring networks yet anticipated to convey more reliable groundwater information for validating the GRACE-based estimates furthermore. The key outcomes of the study summarized below.

1. GRACE derived TWS trends over the NRB and sub-basins evidenced the TWS time series deviations, uncertainties, trends discrepancies, and SNR variations among GRACE solutions of both mascons and SH. Consequently, CSR-M noted the first best performance; GSFC-M is the second-best, followed by JPL-M over NRB and at sub-basins levels. Thus, we recommend CSR-M solutions for detailed water resource studies to minimize uncertainties, especially on hydro-climatological extremes (droughts and floods). 
2. Over the NRB, a significant long-term (2003-2017) negative groundwater and soil moisture trend found in the MNR (Sudan and Egypt), some part in LVR sub-basin (Tanzania \& Kenya) demonstrating a potential depletion. Despite an increase in precipitation and TWS time series, the rate of decline seen to increase rapidly from 2008, thus indicating the possibility of human-induced decline ( e.g., for irrigation purposes). Over the BNR, BER, and LVR sub-basins, negative trends found between January 2003 and September 2006.

3. More considerable spatiotemporal variations of TWS and precipitation recorded over LVR and a lesser degree over the BNR, which can explain more substantial water storage in these regions compared to the MNR (Egypt and Sudan). Contrary to the LVR and BNR, negative trends found for TWS variations over the MNR. In general, negative patterns are observed for water level variation in the MNR and BER regions with the highest (for the period 2003-2006) in contrast to the LVR and BNR.

Availability of data and materials: Data and materials will be made available on request.

Competing interests: The authors declare no conflict of interest.

Funding: We thank the National Natural Science Foundation of China (grant number 41974013 and 41574018) for financial support.

Author Contributions: Zemede M. Nigatu conducted the data analysis and wrote the paper; Dongming Fan and Wei You supervised, verified the methods and results, and revised the manuscript.

Acknowledgments: The GRACE data used in this study are freely accessible from the Science Data Systems Centers websites. The GRACE Level 3 data, as well as supporting documentation, can be accessed from http://podaac.jpl.nasa.gov/grace and http://isdc.gfz-potsdam.de/grace.

Gridded SH mass change data are available from JPL (https://grace.jpl.nasa.gov/), CSR (http://www2.csr.utexas.edu/grace/), and GFZ (http://gravis.gfz-potsdam.de/home). TRMM data accessed from https://disc.gsfc.nasa.gov/data. 


\section{References}

Abtew, W., \& Melesse, A. M. (2014). The Nile River Basin. In A. M. Melesse, W. Abtew, \& S. G. Setegn (Eds.), Nile River Basin: Ecohydrological Challenges, Climate Change and Hydropolitics (pp. 7-21). https://doi.org/10.1007/978-3-319-02720-3_2

Ahmed, M., \& Abdelmohsen, K. (2018). Quantifying Modern Recharge and Depletion Rates of the Nubian Aquifer in Egypt. Surveys in Geophysics, 39(4), 729-751. https://doi.org/10.1007/s10712-018-9465-3

Ahmed, Y., Al-Faraj, F., Scholz, M., \& Soliman, A. (2019). Assessment of Upstream Human Intervention Coupled with Climate Change Impact for a Transboundary River Flow Regime: Nile River Basin. Water Resources Management, 33(7), 2485-2500. https://doi.org/10.1007/s11269-019-02256-1

Andrew, R., Guan, H., \& Batelaan, O. (2017). Estimation of GRACE water storage components by temporal decomposition. Journal of Hydrology, 552, 341-350. https://doi.org/10.1016/J.JHYDROL.2017.06.016

Andrew, R. L., Guan, H., \& Batelaan, O. (2017). Large-scale vegetation responses to terrestrial moisture storage changes. Hydrology and Earth System Sciences, 21(9), 4469-4478. https://doi.org/10.5194/hess-21-4469-2017

Awange, J.L., Forootan, E., Kuhn, M., Kusche, J., \& Heck, B. (2014). Water storage changes and climate variability within the Nile Basin between 2002 and 2011. Advances in Water Resources, 73, 1-15. https://doi.org/10.1016/J.ADVWATRES.2014.06.010

Awange, Joseph L., Sharifi, M. A., Ogonda, G., Wickert, J., Grafarend, E. W., \& Omulo, M. A. (2008). The Falling Lake Victoria Water Level: GRACE, TRIMM and CHAMP Satellite Analysis of the Lake Basin. Water Resources Management, 22(7), 775-796. https://doi.org/10.1007/s11269-007-9191-y

Becker, M., LLovel, W., Cazenave, A., Güntner, A., \& Crétaux, J.-F. (2010). Recent hydrological behavior of the East African great lakes region inferred from GRACE, satellite altimetry and rainfall observations. Comptes Rendus Geoscience, 342(3), 223-233. Retrieved from https://linkinghub.elsevier.com/retrieve/pii/S1631071310000106

Berhanu B., Seleshi Y., Amare M., M. A. M. (2016). Upstream-Downstream Linkages of Hydrological Processes in the Nile River Basin. In Landscape Dynamics, Soils and Hydrological Processes in Varied Climates. https://doi.org/https://doi.org/10.1007/978-3319-18787-7_11

Bonsor, C. H., Shamsudduha, M., Marchant, P. B., MacDonald, M. A., \& Taylor, G. R. (2018). Seasonal and Decadal Groundwater Changes in African Sedimentary Aquifers Estimated Using GRACE Products and LSMs. Remote Sensing , Vol. 10. https://doi.org/10.3390/rs10060904

Bonsor, H., Shamsudduha, M., Marchant, B., MacDonald, A., \& Taylor, R. (2018). Seasonal and Decadal Groundwater Changes in African Sedimentary Aquifers Estimated Using GRACE Products and LSMs. Remote Sensing, 10(6), 904. https://doi.org/10.3390/rs10060904

Castellazzi, P., Martel, R., Galloway, D. L., Longuevergne, L., Rivera, A., \& Castellazzi, P. , Martel, R. , Galloway, D. L., Longuevergne, L. and Rivera, A. (2016). Assessing Groundwater Depletion and Dynamics Using GRACE and InSAR: Potential and Limitations. Groundwater, 54(6), 768-780. https://doi.org/10.1111/gwat.12453

Chambers, D. P., \& Bonin, J. A. (2012). Evaluation of Release-05 GRACE time-variable gravity coefficients over the ocean. Ocean Science, 8(5), 859-868. https://doi.org/10.5194/os-8-8592012

Chen, H., Zhang, W., Nie, N., \& Guo, Y. (2019). Long-term groundwater storage variations estimated in the Songhua River Basin by using GRACE products, land surface models, and in-situ observations. Science of The Total Environment, 649, 372-387. 
https://doi.org/10.1016/J.SCITOTENV.2018.08.352

Chen, J. L., Wilson, C. R., Li, J., \& Zhang, Z. (2015). Reducing leakage error in GRACE-observed long-term ice mass change: a case study in West Antarctica. Journal of Geodesy, 89(9), 925940. https://doi.org/10.1007/s00190-015-0824-2

Cheng, M., Tapley, B. D., \& Ries, J. C. (2013). Deceleration in the Earth's oblateness. Journal of Geophysical Research: Solid Earth, 118(2), 740-747. https://doi.org/10.1002/jgrb.50058

Cleveland, R. B., Cleveland, W. S., McRae, J. E. \& Terpenning, I. (1990). STL: A Seasonal-Trend Decomposition. Journal of Official Statistics, 6, 3-73. Retrieved from http://www.nniiem.ru/file/news/2016/stl-statistical-model.pdf

Conway, D., \& Hulme, M. (1993). Recent fluctuations in precipitation and runoff over the Nile sub-basins and their impact on main Nile discharge. Climatic Change, 25(2), 127-151. https://doi.org/10.1007/BF01661202

D. N. Wiese, D.-N. Yuan, C. Boening, F. W. Landerer, M. M. W. (2018). JPL GRACE Mascon Ocean, Ice, and Hydrology Equivalent Water Height Release 06 Coastal Resolution Improvement (CRI) Filtered Version 1.0. https://doi.org/https://doi.org/10.5067/TEMSC3MJC6.

Di Baldassarre, G., Elshamy, M., van Griensven, A., Soliman, E., Kigobe, M., Ndomba, P., ... P, Mutemi J, Mutua F, Moges S, Xuan J-Q, Solomatine D, U. S. (2011). Future hydrology and climate in the River Nile basin: a review. Hydrological Sciences Journal, 56(2), 199-211. https://doi.org/10.1080/02626667.2011.557378

Duan, X. J., Guo, J. Y., Shum, C. K., \& van der Wal, W. (2009). On the postprocessing removal of correlated errors in GRACE temporal gravity field solutions. Journal of Geodesy, 83(11), 1095. https://doi.org/10.1007/s00190-009-0327-0

Fagiolini, E., Flechtner, F., Horwath, M., \& Dobslaw, H. (2015). Correction of inconsistencies in ECMWF's operational analysis data during de-aliasing of GRACE gravity models. Geophysical Journal International, 202(3), 2150-2158. https://doi.org/10.1093/gji/ggv276

Famiglietti, J. S. (2004, January 1). Remote Sensing of Terrestrial Water Storage, Soil Moisture and Surface Waters. The State of the Planet: Frontiers and Challenges in Geophysics, pp. 197-207. https://doi.org/doi:10.1029/150GM16

Göttl, F., Schmidt, M., \& Seitz, F. (2018). Mass-related excitation of polar motion: an assessment of the new RL06 GRACE gravity field models. Earth, Planets and Space, 70(1), 195. https://doi.org/10.1186/s40623-018-0968-4

Gruber, A., Dorigo, W. A., Crow, W., \& Wagner, W. (2017). Triple Collocation-Based Merging of Satellite Soil Moisture Retrievals. IEEE Transactions on Geoscience and Remote Sensing, 55(12), 6780-6792. https://doi.org/10.1109/TGRS.2017.2734070

Haddeland, I., Clark, D. B., Franssen, W., Ludwig, F., Voß, F., Arnell, N. W., ... Yeh, P. (2011). Multi-model Estimate of the Global Terrestrial Water Balance: Setup and First Results. Journal of Hydrometeorology, 12(5), 869-884. https://doi.org/10.1175/2011JHM1324.1

Hamed, K., \& Ramachandra Rao, A. (1998). A modified Mann-Kendall trend test for autocorrelated data. Journal of Hydrology, 204(1), 182-196.

Hasan, E., Tarhule, A., Kirstetter, P.-E., Clark, R., \& Hong, Y. (2018). Runoff sensitivity to climate change in the Nile River Basin. Journal of Hydrology, 561, 312-321. https://doi.org/https://doi.org/10.1016/j.jhydrol.2018.04.004

Hu, L., \& Jiao, J. J. (2015). Calibration of a large-scale groundwater flow model using GRACE data: a case study in the Qaidam Basin, China. Hydrogeology Journal, 23(7), 1305-1317. https://doi.org/10.1007/s10040-015-1278-6

Humphrey, V., Gudmundsson, L., \& Seneviratne, S. I. (2016). Assessing Global Water Storage Variability from GRACE: Trends, Seasonal Cycle, Subseasonal Anomalies and Extremes. Surveys in Geophysics, 37(2), 357-395. https://doi.org/10.1007/s10712-016-9367-1 
Landerer, F. W., \& Swenson, S. C. (2012). Accuracy of scaled GRACE terrestrial water storage estimates. Water Resources Research, 48(4). https://doi.org/10.1029/2011WR011453

Long, D., Longuevergne, L., \& Scanlon, B. R. (2015). Global analysis of approaches for deriving total water storage changes from GRACE satellites. Water Resources Research, 51(4), 2574 2594. https://doi.org/10.1002/2014WR016853

Loomis, B. D., Luthcke, S. B., \& Sabaka, T. J. (2019). Regularization and error characterization of GRACE mascons. Journal of Geodesy. https://doi.org/10.1007/s00190-019-01252-y

Lu, H., Raupach, M. R., McVicar, T. R., \& Barrett, D. J. (2003). Decomposition of vegetation cover into woody and herbaceous components using AVHRR NDVI time series. Remote Sensing of Environment, 86(1), 1-18. https://doi.org/10.1016/S0034-4257(03)00054-3

Mehrnegar, N., Jones, O., Singer, M. B., Schumacher, M., Bates, P., \& Forootan, E. (2020). Comparing global hydrological models and combining them with GRACE by dynamic model data averaging (DMDA). Advances in Water Resources, 138, 103528. https://doi.org/https://doi.org/10.1016/j.advwatres.2020.103528

Mishra, V., Aadhar, S., Asoka, A., Pai, S., \& Kumar, R. (2016). On the frequency of the 2015 monsoon season drought in the Indo-Gangetic Plain. Geophysical Research Letters, 43(23), 12,102-112,112. https://doi.org/10.1002/2016GL071407

Moore, P., \& Williams, S. D. P. (2014). Integration of altimetric lake levels and GRACE gravimetry over Africa: Inferences for terrestrial water storage change 2003-2011. Water Resources Research, 50(12), 9696-9720. https://doi.org/10.1002/2014WR015506

Multsch, S., Elshamy, M. E., Batarseh, S., Seid, A. H., Frede, H.-G., \& Breuer, L. (2017). Improving irrigation efficiency will be insufficient to meet future water demand in the Nile Basin. Journal of Hydrology: Regional Studies, 12, 315-330. https://doi.org/https://doi.org/10.1016/j.ejrh.2017.04.007

Onyutha, C., \& Willems, P. (2015). Spatial and temporal variability of rainfall in the Nile Basin. Hydrology and Earth System Sciences, 19(5), 2227-2246. https://doi.org/10.5194/hess-192227-2015

Ramillien, G., Frappart, F., \& Seoane, L. (2014). Application of the Regional Water Mass Variations from GRACE Satellite Gravimetry to Large-Scale Water Management in Africa. Remote Sensing, 6(8), 7379-7405. https://doi.org/10.3390/rs6087379

Richard Peltier, W., Argus, D. F., \& Drummond, R. (2018). Comment on "An Assessment of the ICE-6G_C (VM5a) Glacial Isostatic Adjustment Model" by Purcell et al. Journal of Geophysical Research: Solid Earth, 123(2), 2019-2028. https://doi.org/10.1002/2016JB013844

Richey, A. S., Thomas, B. F., Lo, M.-H., Reager, J. T., Famiglietti, J. S., Voss, K., ... Rodell, M. (2015). Quantifying renewable groundwater stress with GRACE. Water Resources Research, 51(7), 5217-5238. https://doi.org/10.1002/2015WR017349

Rodell, M., Houser, P. R., Jambor, U., Gottschalck, J., Mitchell, K., Meng, C.-J., ... Toll, D. (2004). The Global Land Data Assimilation System. Bulletin of the American Meteorological Society, 85(3), 381-394. https://doi.org/10.1175/BAMS-85-3-381

Ryan Hafen. (2016). stlplus: Enhanced Seasonal Decomposition of Time Series by Loess. Retrieved from https://cran.r-project.org/package=stlplus R package version 0.5.1

Sakumura, C., Bettadpur, S., and Bruinsma, S., Sakumura, C., Bettadpur, S., Bruinsma, S., \& Sakumura, C., Bettadpur, S., and Bruinsma, S. (2014). Ensemble prediction and intercomparison analysis of GRACE time-variable gravity field models. Geophys. Res. Lett, 41(5), 1389- 1397. https://doi.org/10.1002/2013GL058632

Save, H., S. Bettadpur, and B. D. T. (2016). High resolution CSR GRACE RL05 mascons. J. Geophys. Res. Solid Earth, 121, 7547- 7569. https://doi.org/doi:10.1002/2016JB013007

Save, H. (2019). CSR GRACE RL06 Mascon Solutions. 
https://doi.org/https://doi.org/10.18738/T8/UN91VR

Save, H., Bettadpur, S., \& Tapley, B. D. (2016). High-resolution CSR GRACE RL05 mascons. Journal of Geophysical Research: Solid Earth, 121(10), 7547-7569. https://doi.org/10.1002/2016JB013007

Scanlon, B. R., Zhang, Z., Save, H., Sun, A. Y., Müller Schmied, H., van Beek, L. P. H., ... Bierkens, M. F. P. (2018). Global models underestimate large decadal declining and rising water storage trends relative to GRACE satellite data. Proceedings of the National Academy of Sciences of the United States of America, 115(6), E1080-E1089. https://doi.org/10.1073/pnas.1704665115

Scanlon, B. R., Zhang, Z., Save, H., Wiese, D. N., Landerer, F. W., Long, D., ... Chen, J. (2016). Global evaluation of new GRACE mascon products for hydrologic applications. Water Resources Research, 52(12), 9412-9429. https://doi.org/10.1002/2016WR019494

Seyoum, W. M. (2018). Characterizing water storage trends and regional climate influence using GRACE observation and satellite altimetry data in the Upper Blue Nile River Basin. Journal of Hydrology, 566, 274-284. https://doi.org/10.1016/J.JHYDROL.2018.09.025

Shamsudduha, M., Taylor, R. G., Jones, D., Longuevergne, L., Owor, M., \& Tindimugaya, C. (2017). Recent changes in terrestrial water storage in the Upper Nile Basin: an evaluation of commonly used gridded GRACE products. Hydrology and Earth System Sciences, 21(9), 4533-4549. https://doi.org/10.5194/hess-21-4533-2017

Sheffield, J., Goteti, G., \& Wood, E. F. (2006). Development of a 50-Year High-Resolution Global Dataset of Meteorological Forcings for Land Surface Modeling. Journal of Climate, 19(13), 3088-3111. https://doi.org/10.1175/JCLI3790.1

Siam, M. S., \& Eltahir, E. A. B. (2017). Climate change enhances interannual variability of the Nile river flow. Nature Climate Change, 7(5), 350-354. https://doi.org/10.1038/nclimate3273

Stoffelen, A. (1998). Toward the true near-surface wind speed: Error modeling and calibration using triple collocation. Journal of Geophysical Research: Oceans, 103(C4), 7755-7766. https://doi.org/10.1029/97JC03180

Sultan, M., Ahmed, M., Sturchio, N., Yan, Y. E., Milewski, A., Becker, R., ... Chouinard, K. (2013). Assessment of the Vulnerabilities of the Nubian Sandstone Fossil Aquifer, North Africa. Climate Vulnerability, 311-333. https://doi.org/10.1016/B978-0-12-384703-4.005311

Swenson, S., \& Wahr, J. (2006). Postprocessing removal of correlated errors in GRACE data. Geophysical Research Letters, 33(8), L08402. https://doi.org/10.1029/2005GL025285

Swenson, S., \& Wahr, J. (2009). Monitoring the water balance of Lake Victoria, East Africa, from space. Journal of Hydrology, 370(1-4), 163-176. Retrieved from https://linkinghub.elsevier.com/retrieve/pii/S0022169409001516

Tangdamrongsub, N., Han, S.-C., Jasinski, M. F., \& Šprlák, M. (2019). Quantifying water storage change and land subsidence induced by reservoir impoundment using GRACE, Landsat, and GPS data. Remote Sensing of Environment, 233, 111385. https://doi.org/10.1016/J.RSE.2019.111385

Thomas, B. F., Caineta, J., \& Nanteza, J. (2017). Global Assessment of Groundwater Sustainability Based On Storage Anomalies. Geophysical Research Letters, 44(22), 11,411445,455. https://doi.org/10.1002/2017GL076005

Uebbing, B., Kusche, J., \& Forootan, E. (2015). Waveform Retracking for Improving Level Estimations From TOPEX/Poseidon, Jason-1, and Jason-2 Altimetry Observations Over African Lakes. IEEE Transactions on Geoscience and Remote Sensing, 53(4), 2211-2224. https://doi.org/10.1109/TGRS.2014.2357893

Vanderkelen, I., van Lipzig, N. P. M., \& Thiery, W. (2018). Modelling the water balance of Lake Victoria (East Africa) - Part 1: Observational analysis. Hydrology and Earth System Sciences, 
22(10), 5509-5525. https://doi.org/10.5194/hess-22-5509-2018

Watkins, MM, Wiese, DN, Yuan, D-N, Boening, C, Landerer, F. (2015). Improved methods for observing Earth's time variable mass distribution with GRACE using spherical cap mascons. J. Geophys. Res. Solid Earth, 20, 2648-2671. https://doi.org/doi: 10.1002/2014JB011547

Wiese, D. N., Landerer, F. W., and Watkins, M. M. (2016). Quantifying and reducing leakage errors in the JPL RL05M GRACE mascon solution. Water Resources Research, 52(9), 74907502. https://doi.org/10.1002/2016WR019344

Wouters, B., Bonin, J. A., Chambers, D. P., Riva, R. E. M., Sasgen, I., \& Wahr, J. (2014). GRACE, time-varying gravity, Earth system dynamics and climate change. Reports on Progress in Physics, 77(11), 116801. https://doi.org/10.1088/0034-4885/77/11/116801

Yang, T., Wang, C., Chen, Y., Chen, X., \& Yu, Z. (2015). Climate change and water storage variability over an arid endorheic region. Journal of Hydrology, 529, 330-339. https://doi.org/10.1016/J.JHYDROL.2015.07.051

Yilmaz, M. T., Crow, W. T., Anderson, M. C., \& Hain, C. (2012). An objective methodology for merging satellite- and model-based soil moisture products. Water Resources Research, 48(11). https://doi.org/10.1029/2011WR011682

Yue, S., Pilon, P., \& Cavadias, G. (2002). Power of the Mann-Kendall and Spearman's rho tests for detecting monotonic trends in hydrological series. Journal of Hydrology, 259(1-4), 254271. https://doi.org/10.1016/S0022-1694(01)00594-7

Yue, S., \& Wang, C. (2004). The Mann-Kendall Test Modified by Effective Sample Size to Detect Trend in Serially Correlated Hydrological Series. Water Resources Management, 18(3), 201218. https://doi.org/10.1023/B:WARM.0000043140.61082.60

Zhang, Y., He, B., Guo, L., \& Liu, D. (2019). Differences in Response of Terrestrial Water Storage Components to Precipitation over 168 Global River Basins. Journal of Hydrometeorology, 20(9), 1981-1999. https://doi.org/10.1175/JHM-D-18-0253.1 
Figures

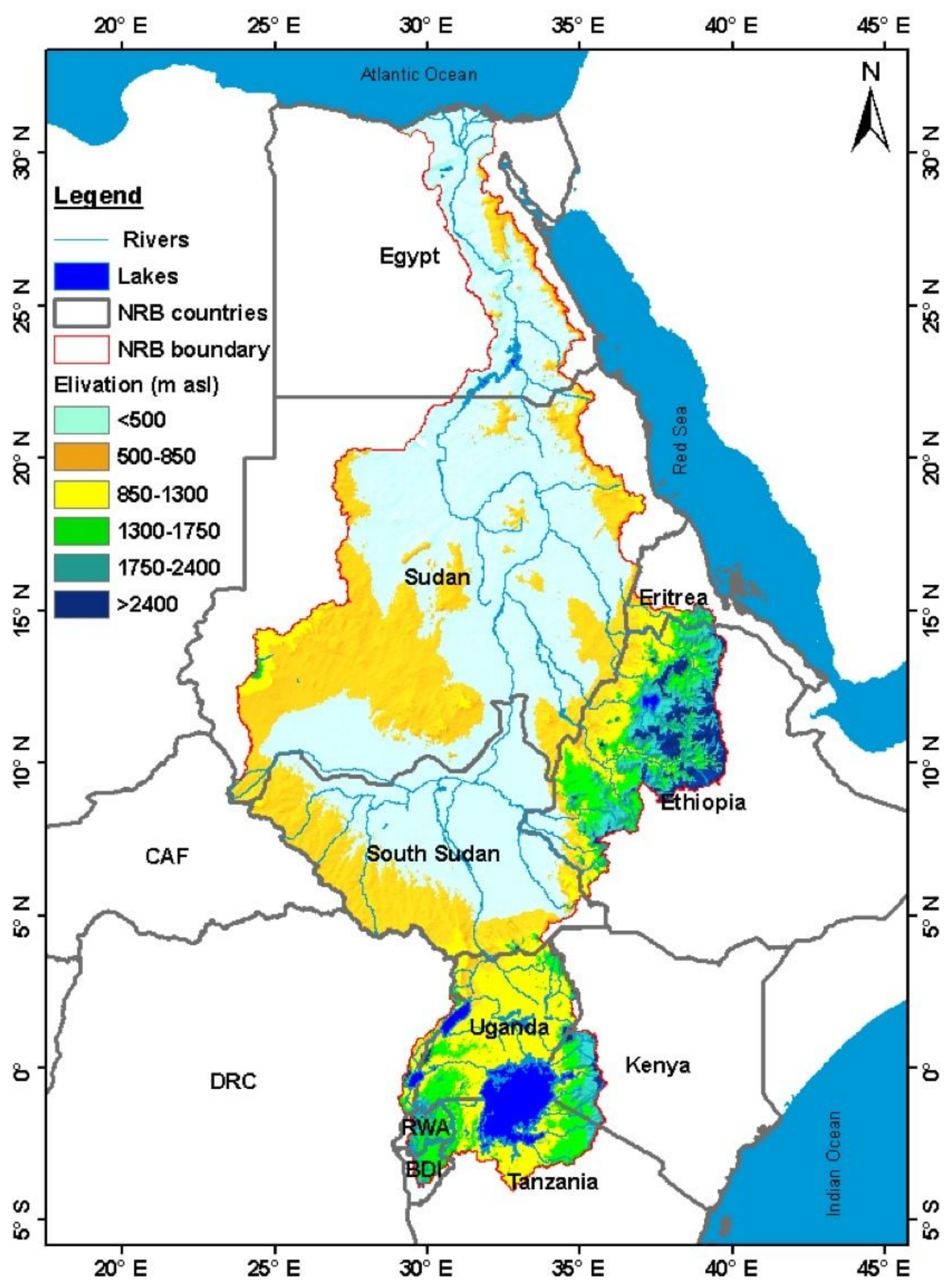

Figure 1

Nile River Basin (NRB) countries, elevation variations, lakes, and rivers 


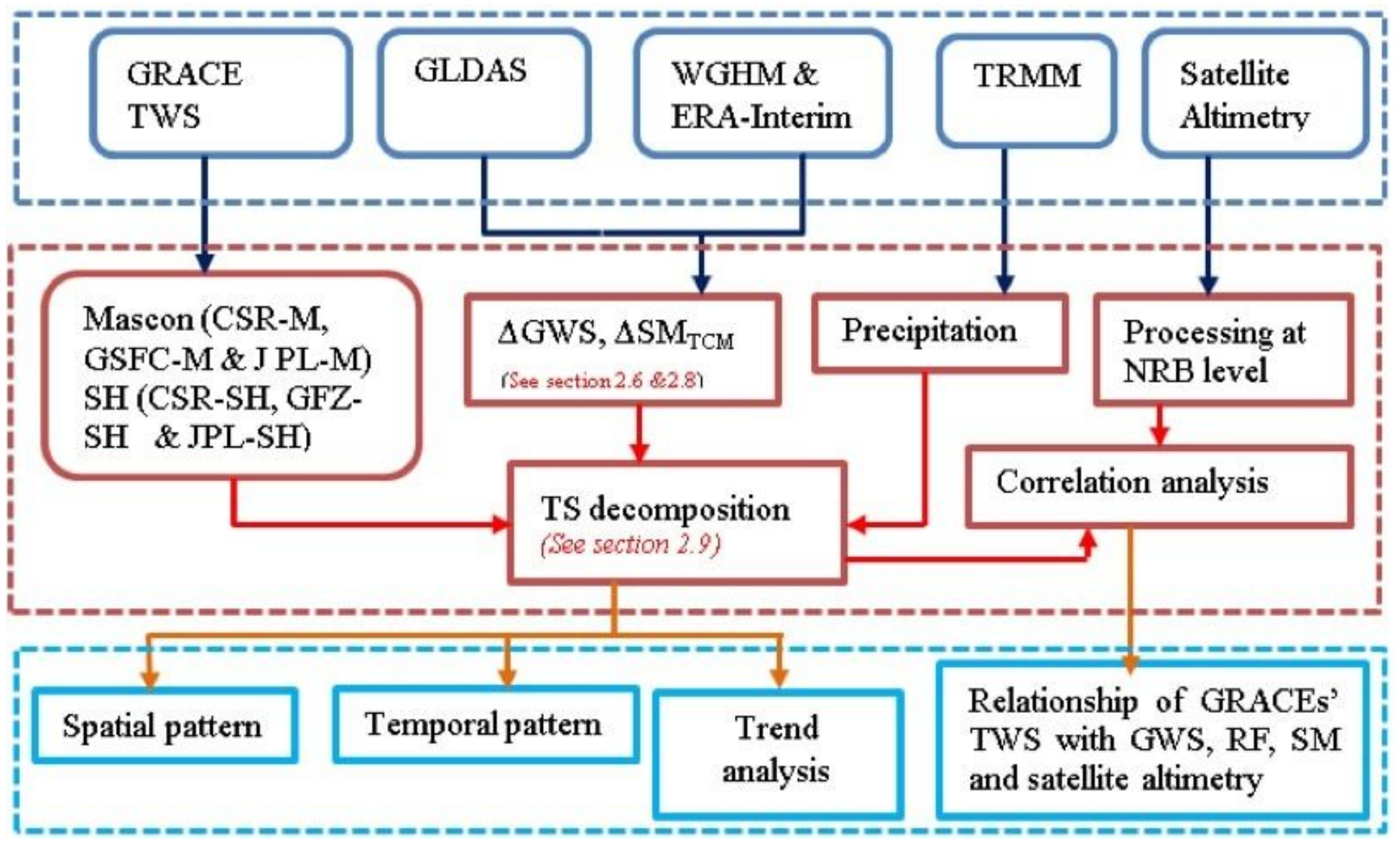

Figure 2

The flowchart of the applied methodology of multi-satellite and multi-models used in this study. 

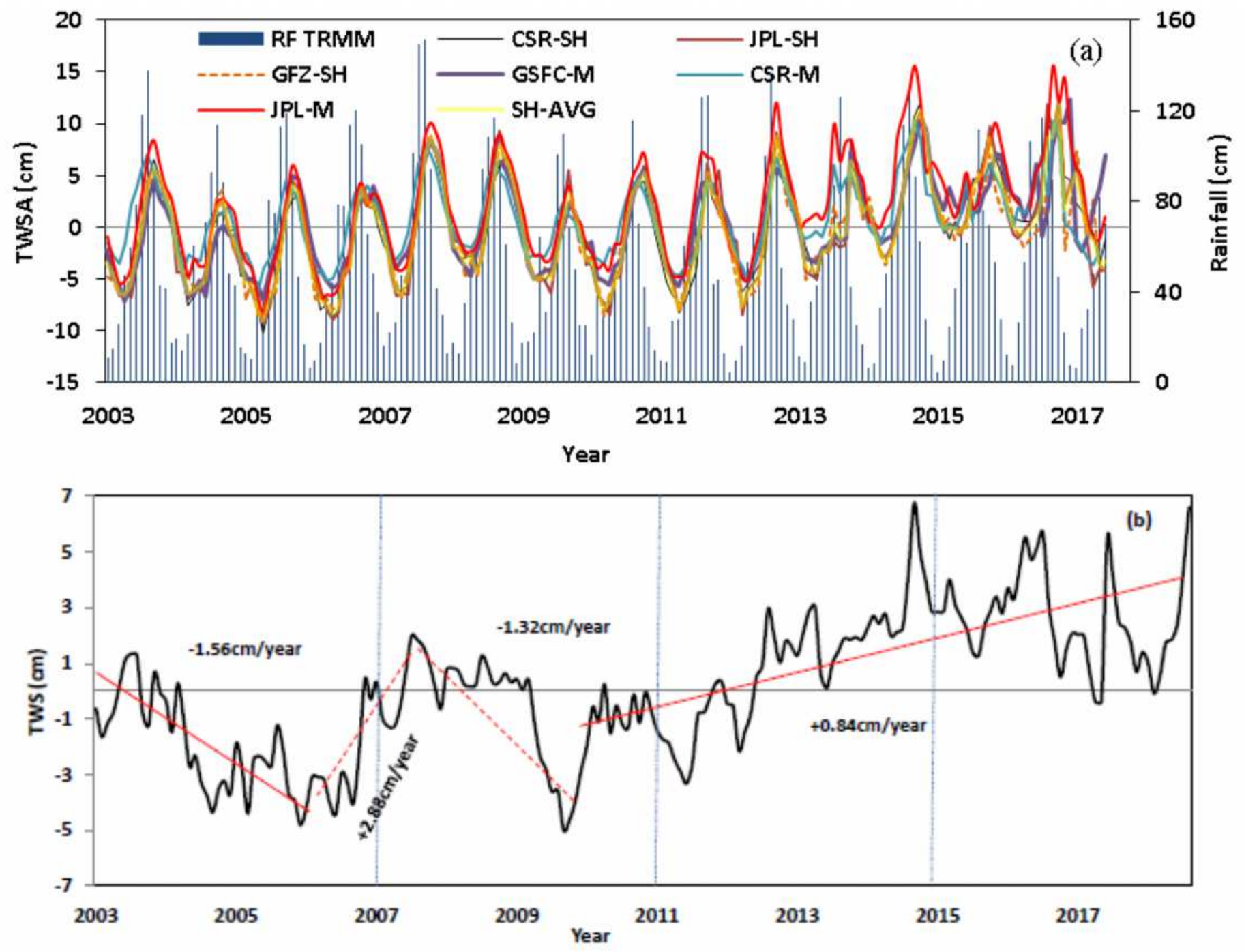

Figure 3

(a) GRACE's TWSA time series in the NRB, (b) CSR-M TWSA time series and trend in the NRB. Note that the dashed-line trend is not statistically significant.
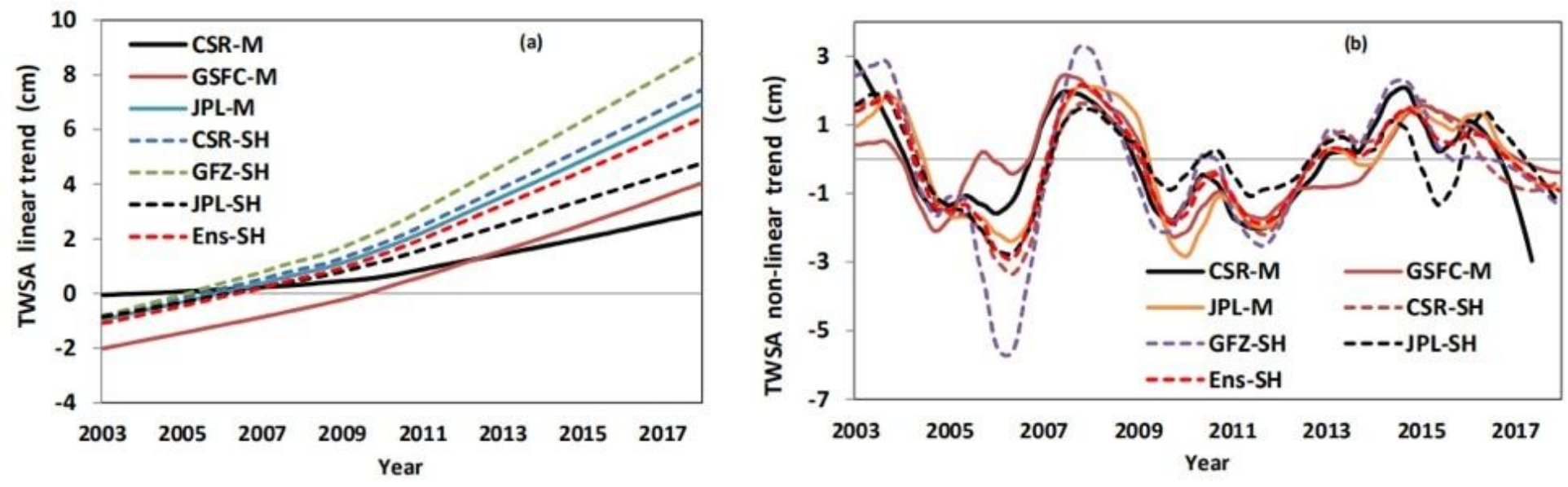

Figure 4 
Trend over NRB (a) long term linear trend, and (b) nonlinear trend ( $\mathrm{cm} /$ year).
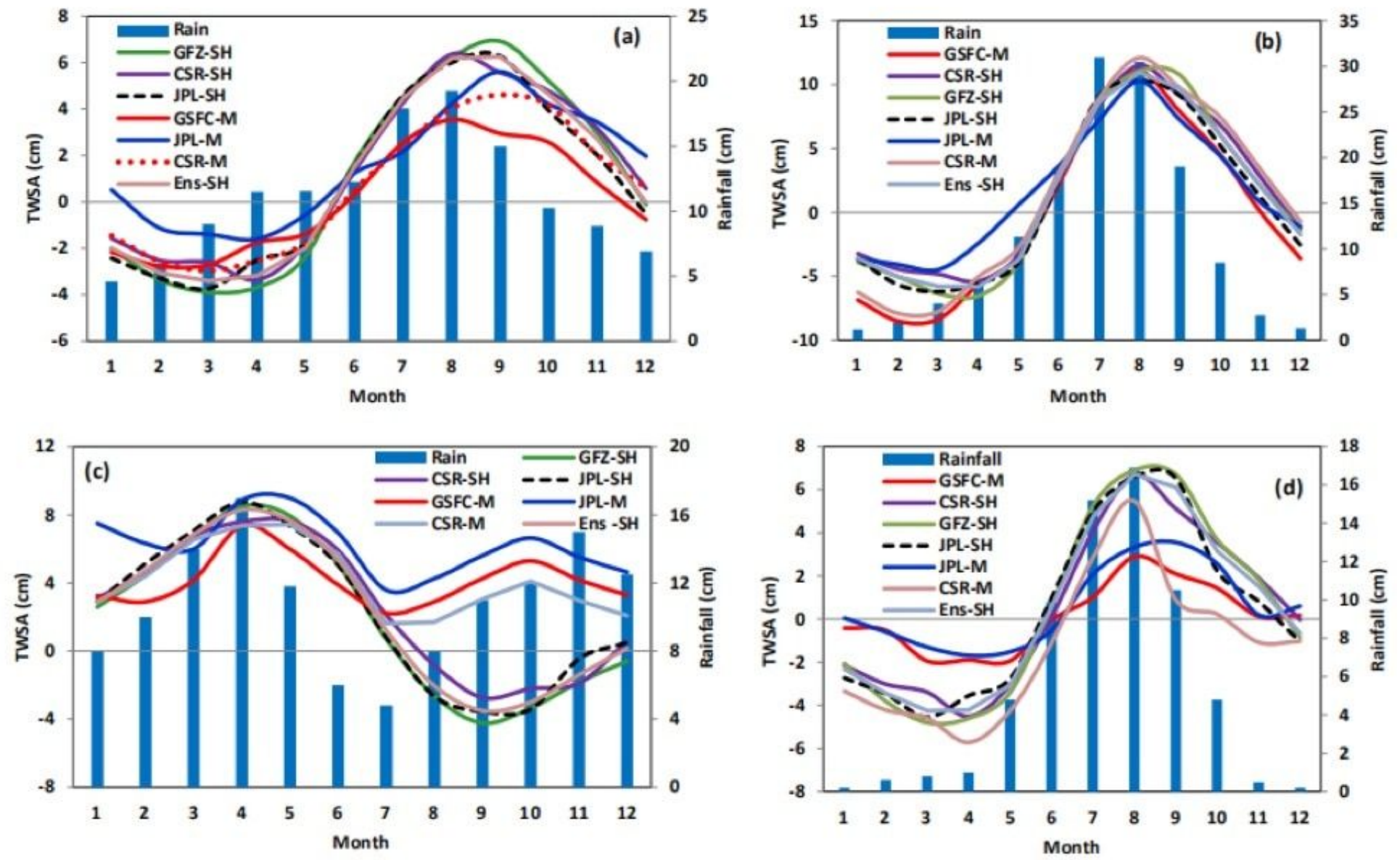

Figure 5

Monthly GRACE's TWS amplitude and rainfall over (a) NRB, (b) Blue Nile River region (BNR), (c) Lake Victoria region (LVR), and (d) Bahr-El-Ghazal region (BER) 

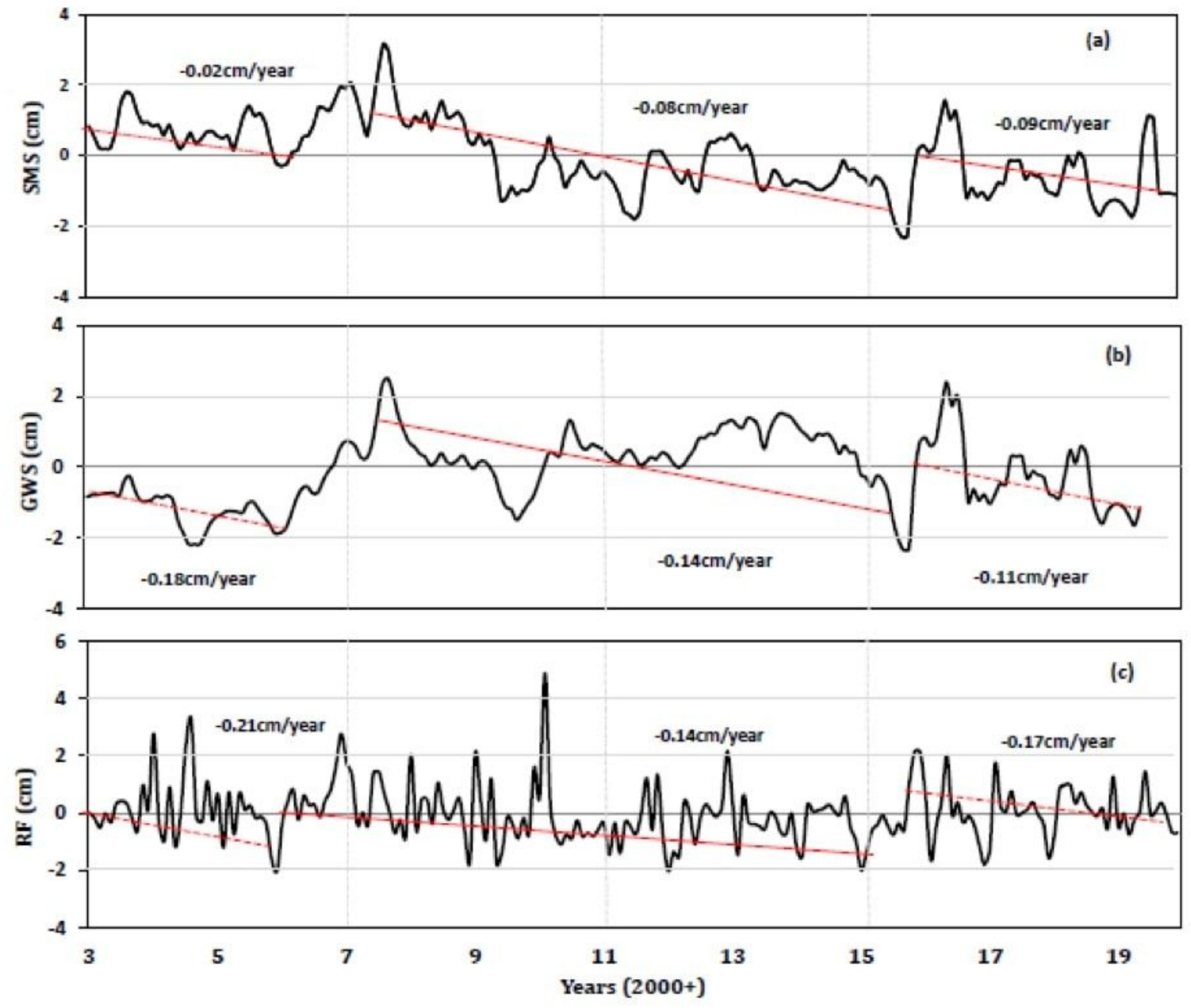

Figure 6

(a) Soil moisture storage (SMS), (b) groundwater storage (GWS), and (c) rainfall (RF) trend of Nile River Basin (after deseasonalizing and removing the long-term mean). Note that the dashed-line trend is not statistically significant. 

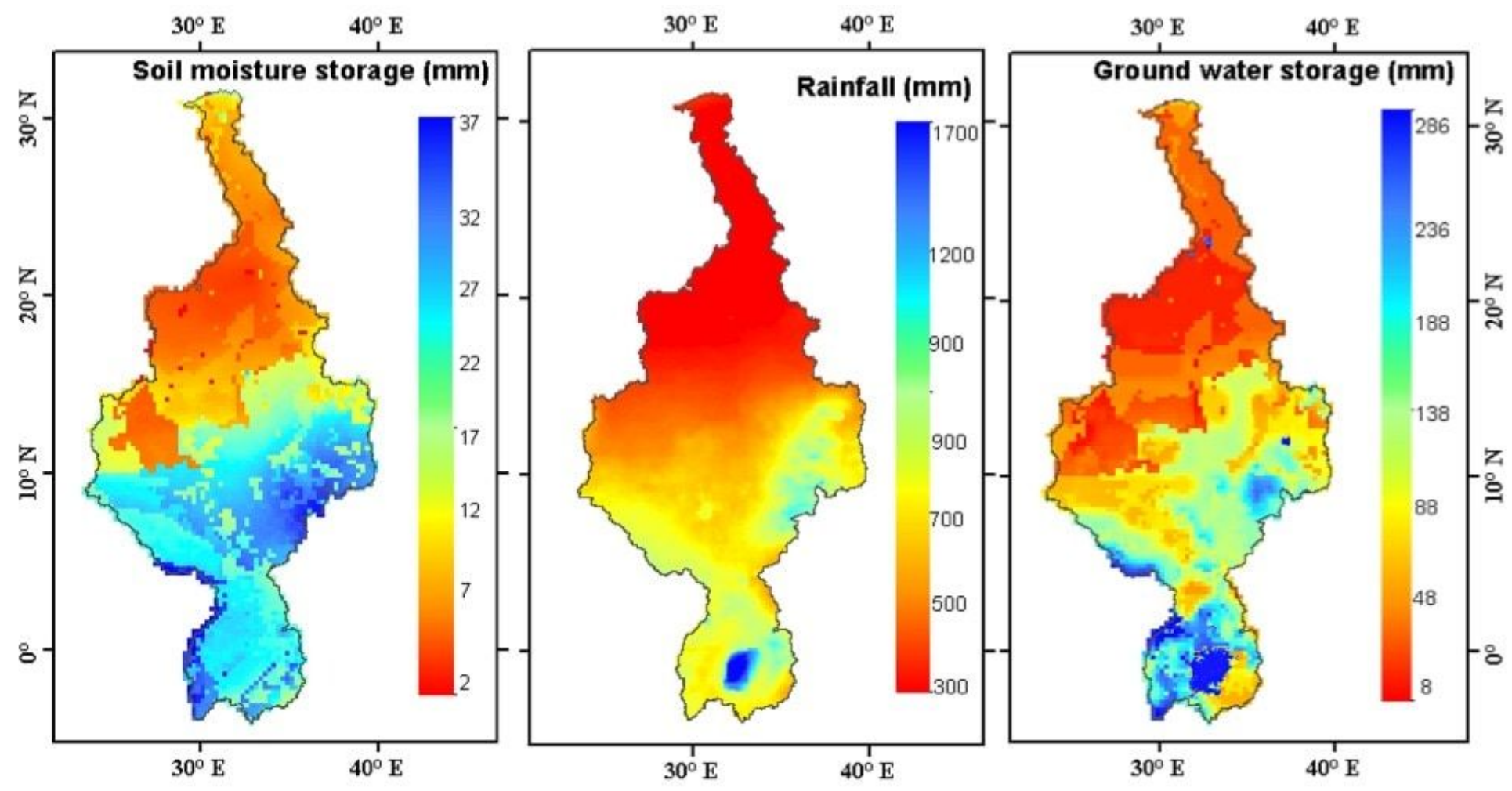

Figure 7

Temporally averaged soil moisture, rainfall, and groundwater over the NRB for the period 2003-2019.
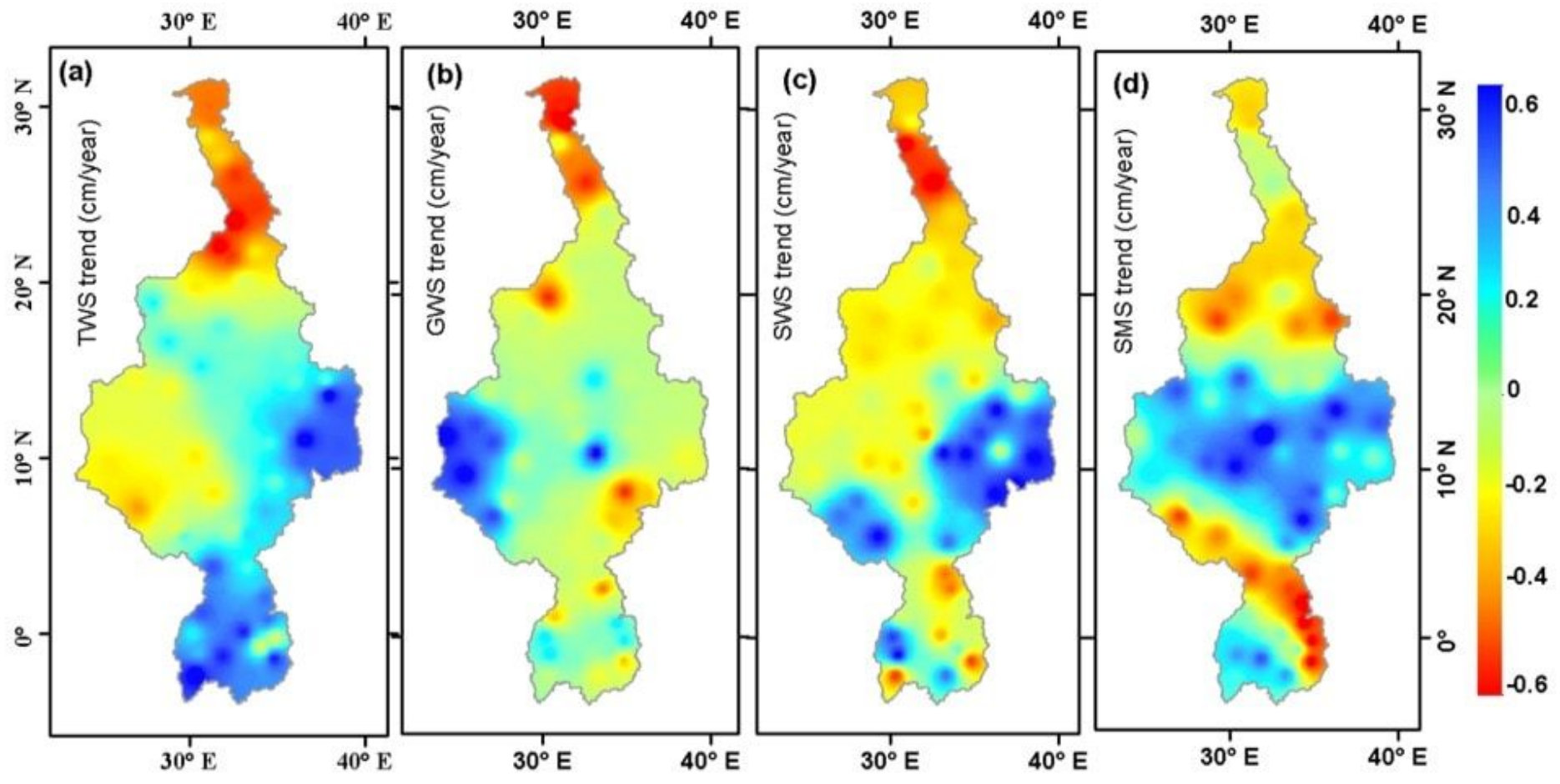

Figure 8

Spatial trend of (a) Terrestrial water, (b) groundwater, (c) surface water, and (d) soil moisture water storage over the NRB for the period of 2003 to 2017. 

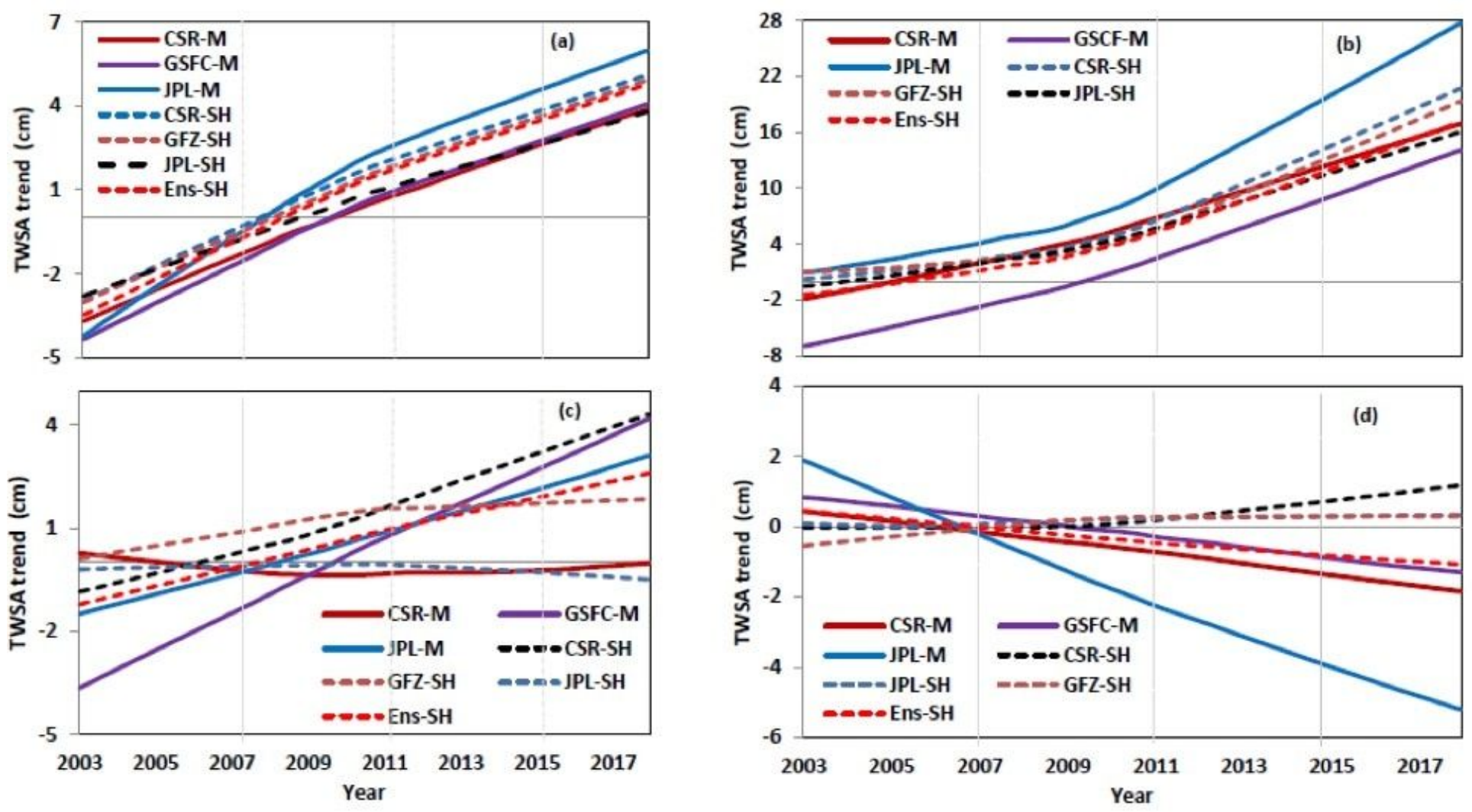

Figure 9

The GRACE's Terrestrial Water Storage Anomaly (TWSA) trend across NRB sub-basins: (a) BNR, (b) LVR, (c) BER, and (d) MNR.

\section{Supplementary Files}

This is a list of supplementary files associated with this preprint. Click to download.

- Tables.docx 